\title{
Optimization of green and low-carbon concept in prefabricated building design
}

\author{
Hongxiong Yang ${ }^{1}$, Yongli Yue ${ }^{2, *}$ \\ ${ }^{1}$ School of Management, Tianjin University of Technology, Tianjin, China. \\ ${ }^{2}$ School of Management, Tianjin University of Technology, Tianjin, China.
}

\begin{abstract}
Prefabricated building, as a representative of modern architecture, has been vigorously promoted, and the traditional problems of large on-site labor and long construction period have been well solved. At present, the development focus of prefabricated building has shifted to the stage of low-carbon, environmental protection, green and energy-saving sustainable development. Whether green and low-carbon design is considered in the planning and design stage has the greatest impact on the whole life cycle of the building. Therefore, this paper mainly summarizes the concept and importance of green and low-carbon building design; The paper points out the embodiment of green and low-carbon concept in prefabricated building design; And how to calculate the carbon emission in the design stage; In view of the prefabricated building design stage to achieve a better green low-carbon state of optimization countermeasures.
\end{abstract}

\section{Introduction}

Traditional building forms are all the components needed to complete the construction project at the construction site, while prefabricated buildings are different. They make use of the form of appointment to produce components, transport the construction to the construction site and assemble prefabricated components according to the procedure, so as to realize the construction of the whole building. From the perspective of advantages, prefabricated buildings are more inclined to the construction form of streamlined production, which is not only conducive to the improvement of the work efficiency of construction personnel, but also can effectively reduce the cost of construction resources. In terms of environmental protection, it also minimizes the environmental damage caused by construction projects, avoids the problem of environmental pollution, effectively implements the concept of green and low-carbon, and further promotes the development of prefabricated buildings towards a more green and environmentally friendly direction. However, from the present expression of green and low-carbon concept in prefabricated building design in China, it is still necessary to further explore how to optimize the application of green and low-carbon in prefabricated building design.

\section{Green and low-carbon building design concept and its importance}

\subsection{The concept of green and low-carbon building design}

As an economy-oriented setting mechanism, the green and low-carbon building concept conforms to the development law of nature. By following the principle of harmonious coexistence between man and nature, the efficiency and output ratio and energy consumption ratio of the whole building structure can reach an equilibrium point in the period when the whole building structure damages the natural environment. In green low carbon building design process, itself is energy conservation and emissions reduction as the core, the consumption of natural resources and the available resources for effective integration, to ensure the whole building can sustain the use of the industry itself can maximize the value and the ecological environment to form an organic whole, and for the development of construction industry in China to provide a sustainable FaZhanDian. Green low carbon building design another important point is to guarantee the sustainable use of energy, using new energy to replace the traditional energy consumption, ensure all kinds of resources to present a sustainable and renewable characteristics, such as wind, water, etc., through the rational utilization of resources, can effectively reduce the whole construction process of the production of waste, and other resources reasonable use, and can effectively ensure the construction area for ecological environment protection plays a good role in promoting. With the continuous improvement of people's quality of life, green and low-carbon construction technology is more suitable for people's living needs. It is guaranteed that the implementation of building technology is based on people's needs through the fit of comfort. For example, in the selection of building materials, they are mainly original and pollution-free materials, and they will not produce all kinds of substances harmful to the surrounding

\footnotetext{
* Corresponding author: 1511493496@qq.com
} 
environment and living environment during the consumption process, so as to build a good ecological environment for people's living places.

\subsection{The importance of green and low-carbon building design}

In recent years, the rapid and stable development of national economy is based on the excessive consumption of social resources and natural resources to achieve economic growth. When the rate of economic development is higher than the rate of environmental protection, serious ecological problems will occur, and even endanger the healthy life and work of human beings. At this stage in the construction industry to adopt green low carbon design concept, to a certain extent, can avoid caused by environmental pollution and ecological imbalance, due to the design work in the whole construction process is a very important part, and ultimately building products is the embodiment of the design concept, so green, low carbon design concept for the whole construction process of the implementation of low carbon environmental protection effect is greatly influenced[1].

The importance of building design under the concept of green and low-carbon is mainly divided into the following points: First, building design under the concept of green and low-carbon is the remedial measures taken at the present stage for the damage and damage brought to the society by the development supported by traditional energy. The architectural design under the concept of low carbon and energy saving can change the environmental problems caused by the economic development mode supported by traditional industry, such as climate deterioration, environmental pollution and soil erosion. It can help realize the highly unified development of the construction industry and the social economy, and promote the healthy and sustainable development of China's economy. Secondly, and corresponds to the consumer demand, in accordance with the concept of green low carbon design, can effectively guarantee the whole building can meet the pressing needs of the people for a better home, guarantee in the whole ecological environment is not destroyed or under the condition of little damage, make the structure of the residential, commercial, etc., thus improving the living quality of buildings. Finally, the proposal and setting of the concept of green and low-carbon is an important guiding mechanism in the development process of the construction industry. Through the introduction of new technology, new technology, the whole construction industry to form a sustainable development trend. As the pillar industry of China's economic development, the construction industry radiates from all aspects of society[2]. Therefore, the green and low-carbon construction industry can play a demonstrative role in all walks of life in society, so as to drive the sustainable development of other industries, further enhance the environmental protection concept of the industry and individuals, and promote the sustainable development of society.

\section{Green and low-carbon concept is mainly embodied in prefabricated building design}

\subsection{The embodiment of green and low-carbon concept in building materials}

\subsubsection{External wall insulation and construction of prefabricated buildings}

Different from previous buildings, the exterior wall design of prefab buildings can better meet the requirements of residents. According to the different changes in region, climate and temperature, the exterior wall of prefab buildings can retain the individuality and at the same time have a better energy saving effect than traditional buildings[3]. Generally, in the early stage of the design of prefabricated buildings, the external walls will adopt hanging boards and heat preservation and insulation boards to ensure that the indoor temperature can be adjusted through the corresponding heat convection generated by ventilation between hanging boards and heat insulation boards, even in a high temperature state. On the other hand, composite prefabricated building walls also need to be designed with an insulation layer made of thermal insulation performance materials to ensure that the indoor temperature can be well regulated even if the temperature is low. This requires that in the process of exterior wall design, attention should be paid to the structure of the sexy exterior wall and the cold temperature perception test, which is conducive to ensuring that the temperature sensitivity and specification parameters of the wall are within the standard requirements, as well as the quality control of the external wall.

\subsubsection{Roofing and exterior Windows of prefabricated buildings}

In the roofing structure design of prefabricated buildings, the commonly used structural forms are waterproof panel, heat preservation panel, etc., and the load materials such as insulation board and cement composite board are the main construction materials of roofing structure. Building metope is needed in the specific operation, the first fixed composite cement, thermal insulation board, followed by coating filling to sandwich panels, insulation waterproof processing, finally is apply a layer of mud mixed layer thickness is about $25 \mathrm{~mm}$, is used for roof heat transfer is reduced, the temperature of the roof will not be too high[4] In addition to the walls, the external Windows of prefabricated buildings are also changed. In the design of the external Windows, the traditional single-layer glass is no longer relied on only, but double-layer hollow plastic steel window glass is selected to meet the use of the external Windows of prefabricated buildings, so as to achieve better thermal insulation effect. At the same time, the floor treatment of prefabricated buildings is also different from the traditional design. In the choice of materials, it is necessary to consider the suitable materials required by the different floor thickness. For example, 
cement mortar is generally applicable to the $20 \mathrm{~mm}$ or so thickness of the ground surface layer, and more than $60 \mathrm{~mm}$ of the ground surface layer needs to consider composite insulation board[5].

\subsection{The embodiment of green and low-carbon concept in design technology}

Low-carbon materials and energy-saving technologies are not only applied in architectural design. At present, the application of new energy technologies can well solve the problem of energy consumption in architectural design. For example, in the process of building design, solar energy can be converted into heat energy to provide hot water, or converted into light energy to provide night lighting. In the form of photothermal and photoelectric conversion, energy can be kept clean while reducing the building energy use cost, so as to realize energy saving. Energy saving technology is also reflected in the design of energy saving and insulation design for building heating in cold areas, which can effectively reduce energy consumption. In cold areas, the architectural design should reduce indoor and outdoor heat transfer as much as possible, adopt geothermal heating and other new heating methods instead of traditional energy heating, and reduce environmental pollution. Through the building design of energy saving technology, and then realize the establishment of energy saving building system, to achieve the purpose of green and low-carbon design.

Although the concept of green and low carbon is embodied in the above two aspects in prefabricated building design, it is not enough to present the concept of green and low carbon in prefabricated building design at present. There are still problems such as excessive carbon emission and waste of resources, which need to be measured by new technologies and optimized countermeasures are proposed.

\section{Calculation procedure and model of carbon emission in prefabricated building design stage}

Design planning stage refers to the unit from beginning to the end of the planning task project, through the space form of design, the choice of building materials, construction equipment system, determine the construction of the overall situation, to the management of the whole life cycle of the building, the key is in the design phase will fully consider, from planning to use, discard the entire life cycle of seeking comprehensive optimal solution. As for the low-carbon nature of buildings, in the planning and design stage, the low-carbon construction standard of the project should be firstly determined according to the goals of urban and social development, and then the design department should carry out various designs of buildings under the limits of this standard. Architectural design by drawing expression of building the information, determine the structure of the basic features, and by the design results confirm whether low carbon buildings, the construction of low carbon buildings, need at the design stage to predict the whole life cycle of carbon emissions of the building, through quantitative analysis, on the structure of the low carbon to decide and audit.

It is the first and most important step to judge whether the architectural design meets the low-carbon requirements of the project, limit the carbon emission according to the standard and adjust the design until it meets the low-carbon building standard. In this stage, Revit modeling software is used for modeling design of engineering projects. Figure 1 shows the steps and contents of carbon emission calculation in the design and planning stage, and Figure 2 shows the composition of the carbon emission calculation platform in the design and planning stage.

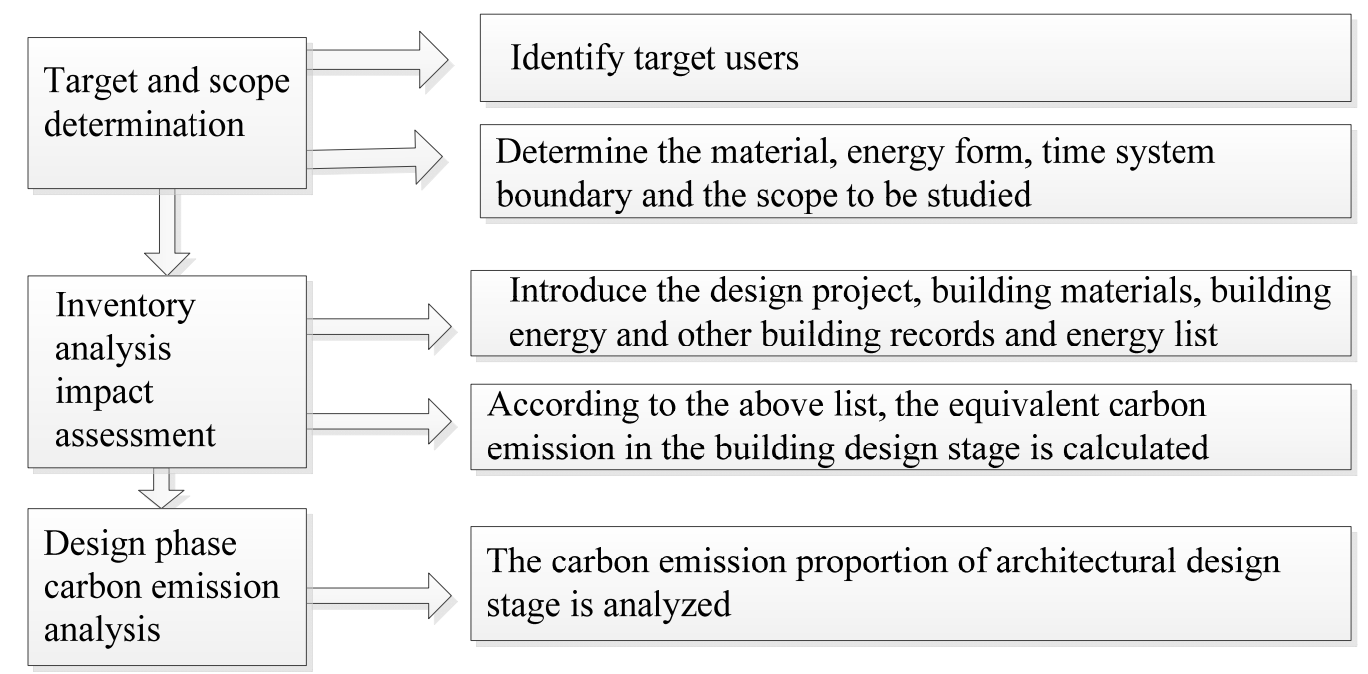

Fig. 1. Steps and contents of carbon emission calculation in the design stage 


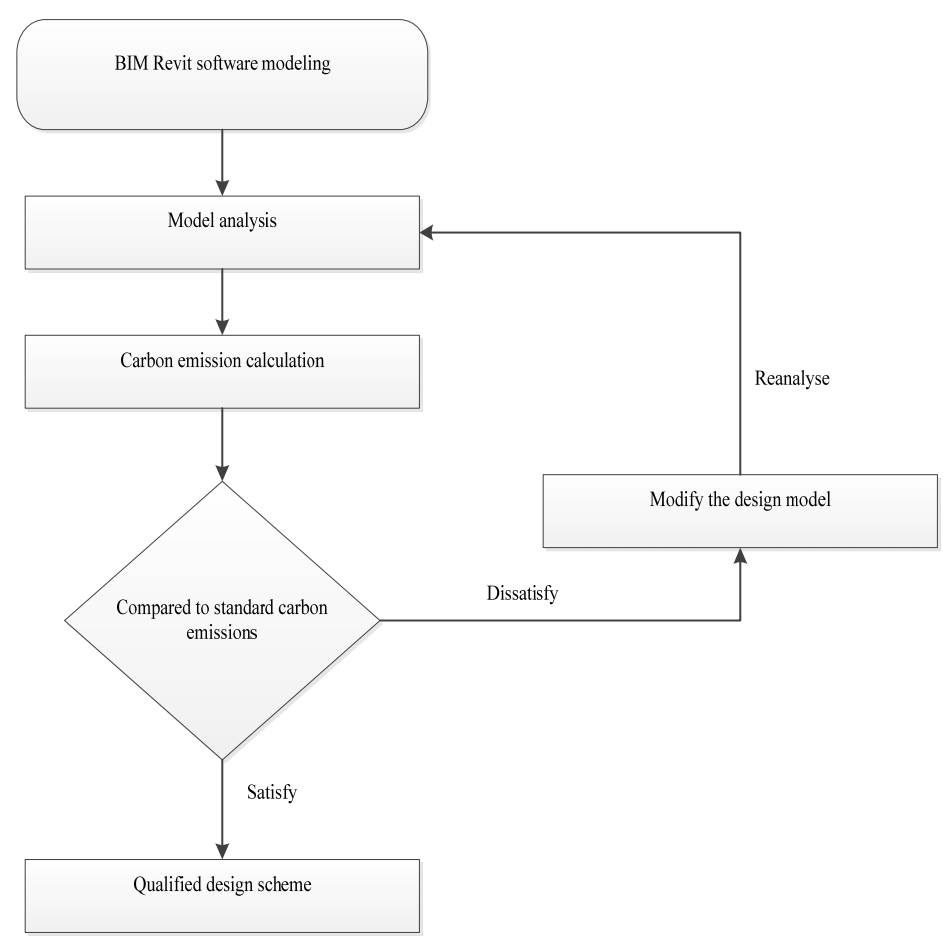

Fig. 2. Composition of the carbon emission platform in the design stage.

\section{Conclusions}

The implementation of green and low-carbon concept in prefab building design is very important for architectural design, and it is also the call of the new era for an environment-friendly society. The key to the green and low-carbon design concept is energy conservation. At present, China vigorously advocates the strategy of green and sustainable development. Although the concept of green and low carbon is embodied in the current prefab building design, it still fails to meet the national standard of carbon emission. In addition, carbon emission measurement should be carried out in the design stage, and each design scheme should be improved and perfected to better meet the harmonious coexistence between the building and the environment during the building process. In order to better promote the technical progress of prefabricated building industry, popularize the green and low-carbon design concept comprehensively, implement it in the practice of building projects, and ensure the construction industry to achieve a win-win situation of economic benefits and social benefits, the following optimization countermeasures are proposed in the design.

(1)Strengthen the green and low-carbon consciousness of prefabricated building designers. Only by building a sense of green and low-carbon can designers better integrate it into their designs, rather than compromise to meet some environmental target. In the design process, architectural designers need to integrate the overall design content of prefabricated buildings into the current social environmental protection demand, give full play to innovative thinking on a solid theoretical basis, and combine their theoretical knowledge to realize green and low-carbon prefabricated buildings with advanced technologies. Therefore, in the training process of architectural designers, it is necessary to establish an effective architectural design training system to enhance designers' awareness of architectural environmental protection issues. Building designers should establish the awareness of green building and improve their professional skills. Cultivating high-quality design talents with green and low carbon consciousness is the premise of realizing green building.

(2)Strengthen green and low-carbon technological innovation in prefabricated buildings. Technological innovation is fundamental to the development of the industry. Only through continuous technological innovation can the promotion and development of green and low-carbon architecture be guaranteed. Based on the current new situation, the realization of green and lowcarbon prefabricated buildings requires the full utilization of resources and the reduction of energy consumption, as well as the vigorous research and development and application of environmental protection materials and technologies[6]. The innovation and promotion of energysaving technology in the design can not only effectively reduce the waste of resources, fully and rationally allocate resources, but also make the design more in line with the requirements of sustainable development of The Times.

(3)Pay attention to the balance between economic benefits and ecological benefits. The construction industry has a high requirement for economic benefits, so the main purpose of most buildings in the design process is to obtain greater economic benefits, while ignoring environmental protection and reducing energy consumption. Prefabricated construction, therefore, designers must fully realize the importance of green low carbon design, in the architectural design, for the entire project construction process of a targeted at various stages of ecological benefit and economic benefit analysis, effectively reduce the 
construction cost, enhance the economic efficiency of project construction, the economic benefit and ecological benefit into the scope of design considerations, in the control of construction cost at the same time to two or morethings environmental benefit, economic benefit and ecological benefit balance.

\section{References}

1. Liu Jiaping, Zhu Xiaolin. Green Building in the Era of Building Industrialization [J]. Jiangsu Architecture, 2018(06):1-3.

2. Chen Xuekai, Chen Chen, Guo Yajie. An Analysis of architectural Design Strategies under the concept of low carbon [J]. Residential Buildings,2020(24):124125 .

3. Gao Xiong, Li Liheng, Li Jianhong. Preliminary Study on environmental Protection Design of prefabricated Building Structures [J]. Resource Conservation and Environmental Protection, 2019(04):188.

4. Lin Xiong. Prefabricated Building Technology Analysis based on green and low-carbon Environmental Protection [J]. Green Building Materials, 2020(12):27-28.

5. Chou Duorong, Wang Huasheng. Research on architectural decoration design based on the concept of low-carbon economy [J]. Journal of shandong agricultural engineering university,2019,36(08):2627.

6. Jiang Gefen. Analysis of Architectural Design Methods and Technologies under the concept of low Carbon and Energy Saving [J]. Residential \& Real Estate, 2018(18):89. 